\title{
Selection of a Mutant of Bacillus subtilis Deficient in Glucose-6- phosphate Dehydrogenase and Phosphoglucoisomerase
}

\author{
By JU-YUAN LIN* AND CHANDAN PRASAD† \\ Laboratory of Molecular Biology, NINDS-NIH, U.S. Department of Health, \\ Education and Welfare, Bethesda, Maryland $200 \mathrm{I} 4$, U.S.A.
}

(Received I April 1974)

INTRODUCTION

The addition of glucose or other rapidly metabolized carbon compounds into a nutrient sporulation medium suppresses sporulation of Bacillus subtilis cells (Freese, Oh, Freese, Diesterhaft \& Prasad, 1972). The first step in glucose metabolism in B. subtilis (strain 600 I 5) involves phosphorylation to glucose-6-phosphate (G6P), which may either be isomerized to fructose-6-phosphate by phosphoglucoisomerase (PGI) or oxidized to gluconate-6-phosphate by G6P-dehydrogenase (G6PD) (Prasad, Diesterhaft \& Freese, 1972).

A mutant lacking only PGI activity (strain 6II58) grows slowly on glucose (Freese et al. I972), utilizing the hexose monophosphate shunt; a derivative of this strain that lacked also an enzyme of the shunt ought not to grow on glucose at all. We have isolated such a mutant. All media, such as the minimal salt medium N, tryptose blood agar base (TBAB), and the phosphate-magnesium buffer PM, were as described by Freese et al. (1972).

\section{RESULTS AND DISCUSSION}

Strain 61158 was grown in $\mathrm{N}$ medium containing $0.5 \%$ glucose and $0.0 \mathrm{r} \%$ casein hydrolysate to $A_{600}=0.7$ to 0.8 . Cells were collected by centrifugation ( $10000 \mathrm{~g}$ for $10 \mathrm{~min}$ at $4{ }^{\circ} \mathrm{C}$ ) and washed with PM buffer. The washed cells were treated for 90 min at $37^{\circ} \mathrm{C}$ with $5 \mathrm{~mm}$-ethylmethanesulphonate. Treated cells were washed twice with PM buffer, resuspended in $N$ medium containing $0.5 \%$ gluconate and $0.01 \%$ casein hydrolysate, and then shaken on a waterbath shaker ( 20 strokes $/ \mathrm{min}, 37^{\circ} \mathrm{C}$ ) for $2 \mathrm{~h}$. The cells were diluted in PM and plated on TBAB plates. After overnight incubation at $37^{\circ} \mathrm{C}$, the colonies were replicated on $\mathrm{N}+0.5 \%$ glucose agar plates. Isolates unable to grow on glucose were assayed for G6PD, PGI, and gluconate-6-phosphate dehydrogenase (GCN-6-PD) activities, as described earlier (Freese et al. 1972; Prasad et al. 1972). One isolate (strain 6r 324) showed a low activity for G6PD $(<20 \%$ that of the parent, strain 6II58). This mutant grew on plates containing $\mathrm{N}+0.5 \%$ glycerol, malate, citrate, or gluconate but not on glucose or fructose (Table $\mathrm{I}$ ). The lack of growth of strain 61324 on fructose was inherited from its parent, strain 61 158 , and it was unrelated to the G6PD or PGI mutations (C. Prasad and E. Freese, unpublished).

Since G6PD deficiency in strain 6r 324 appeared to be leaky, the properties of normal and mutant enzymes were examined in crude extract preparations. At $5 \mathrm{~mm}-\mathrm{G} 6 \mathrm{P}$ and using $50 \mathrm{~mm}-N$-tris(hydroxymethyl)methyl-2-aminoethane-sulphonic acid (TES), the G6PD activity was similar at all $\mathrm{pH}$ values for both enzymes. A significant difference in the $K_{m}$

* Present address: Department of Biochemistry, Georgetown University, Washington, D.C. 20007, U.S.A.

$\dagger$ Present address: Laboratory of Biochemical Genetics, National Heart and Lung Institute, National Institutes of Health, Bethesda, Maryland 20014, U.S.A. All correspondence to C.P. 


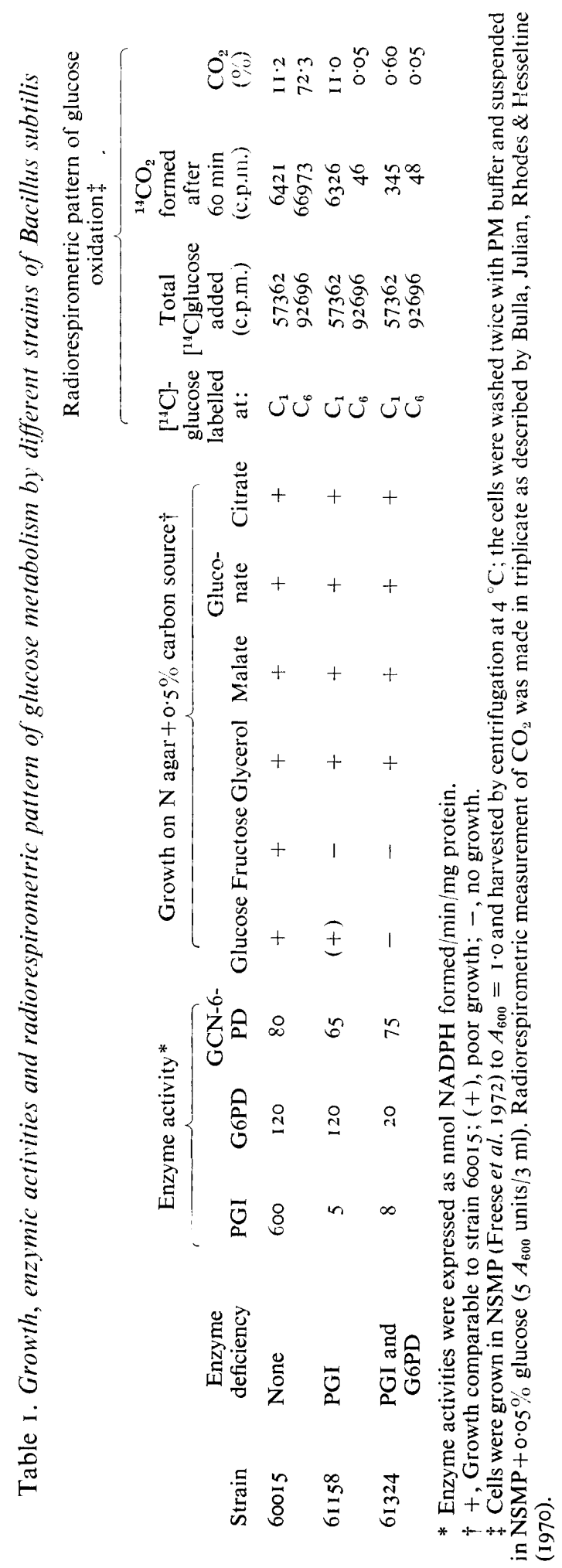


(G6P) values for the two enzymes (in $50 \mathrm{~mm}-\mathrm{K}-\mathrm{TES}, \mathrm{pH} 8 \cdot 0$ ) was observed. The $K_{m}(\mathrm{G} 6 \mathrm{P})$ for the mutant enzyme ( $35 \mathrm{~mm})$ was 175 times higher than that of normal enzyme $(0 \cdot 2 \mathrm{~mm})$.

Table $I$ also shows the radiorespirometric pattern of metabolism of $\left[{ }^{14} \mathrm{C}\right]$ glucose labelled at $C_{1}$ and $C_{6}$ by strains 600 I 5, 6I I 58 and 6I324. Since $C_{1}$ and $C_{6}$ of glucose are metabolised through the hexose monophosphate shunt and the Embden-Meyerhof pathway, respectively (Mahler \& Cordes, I966), the levels of $\mathrm{CO}_{2}$ production from $\mathrm{C}_{1}$ and $\mathrm{C}_{6}$ in strain 600I5 demonstrated that the Embden-Meyerhof pathway is the major route of glucose-metabolism in B. subtilis. In strain 61324, like strain 6I I58, the Embden-Meyerhof pathway is nonfunctional due to the PGI mutation, whereas the hexose monophosphate shunt is operating at a very low efficiency due to the leakiness of G6PD.

G6PD and PGI are widely occurring enzymes. Several possible roles in metabolism have been suggested (Mahler \& Cordes, 1966). These include glucose oxidation by the EmbdenMeyerhof pathway and the hexose monophosphate shunt, the formation of pentose, and the reduction of nicotinamide adenine dinucleotide phosphate. Mutations leading to G6PD deficiency have also been implicated with haemolytic anaemia in man (Beutler, I966) and morphological variations in Neurospora crassa (Lechner, Fuscaldo \& Bazinet, 1971). Comparison of the characteristics of normal cells and mutants lacking these enzymes in B. subtilis may clarify the situation.

\section{REFERENCES}

Beutler, E. (1966). Glucose-6-phosphate dehydrogenase deficiency. In Metabolic Basis of Inherited Disease, pp. I060-1089. Edited by J. B. Stanbury, J. B. Wyngaarden and D. S. Frederickson. New York: McGraw Hill.

Bulla, L., Julian, G. S., Rhodes, R. A. \& Hesseltine, C. W. (1970). Physiology of sporeforming bacteria associated with insects. I. Glucose catabolism in vegetative cells. Canadian Journal of Microbiology I6, $243-248$.

Freese, E., Oh, Y. K., Freese, E. B., Diesterhaft, M. D. \& Prasad, C. (i972). Suppression of sporulation. In Spores, vol. 5, pp. 21 2-22 I. Edited by H. O. Halvorson, R. S. Hanson and L. L. Campbell. Washington, D.C.: American Society for Microbiology.

Lechner, J. F., Fuscalso, K. E. \& Bazinet, G. (I97I). Genetic and biochemical studies of the hexose monophosphate shunt in Neurospora crassa. II. Characterization of biochemical defects of the morphological mutants colonial 2 and colonial 3. Canadian Journal of Microbiology 17, 789-794.

Mahler, H. R. \& Cordes, E. H. (I966). Biological Chemistry, pp. 448-454. New York: Harper and Row.

Prasad, C., Diesterhaft, M. D. \& Freese, E. (1972). Initiation of spore germination in glycolytic mutants of Bacillus subtilis. Journal of Bacteriology 110, 32 1-328. 